DOI 10.1007/s10958-019-04564-8

Journal of Mathematical Sciences, Vol. 243, No. 5, December, 2019

\title{
ALEXANDER PAVLOVICH KACHALOV MARCH 27, 1949 - OCTOBER 1, 2017
}

The whole life of Alexander Pavlovich was devoted to mathematics ever since he (at that time schoolboy Sasha from the village Kuzmolovo in the Leningrad region) entered the physical and mathematical boarding school at the faculty of mathematics and mechanics of Leningrad State University.

This boarding school had a purpose "to catch a gold fish (a talent for physics or mathematics) and to properly educate and train the caught fish." Among the graduates of the boarding school, there are many known scientists and science organizers. From a large list I will give only three names: A. A. Bolibrukh, I. A. Panin, and S. V. Kislyakov. Now the boarding school is named the D. K. Faddeev Academic Gymnasium of St. Petersburg State University.

After the boarding school it was natural for Sasha to enter the math-mech faculty, however the path to science for Sasha was not smooth. On graduating from the university (1970), he was assigned to work in the Scientific Research Institute of Magnetodielectrics. Later Sasha was mobilized and worked for two years in the defence industry. Only after these four years of work in the military institutions, he goes to the LOMI graduate school (1975). Further it was the traditional path of a mathematician: Ph. D. thesis, Doctoral thesis, work on papers and a monography.

Investigations of A. P. Kachalov were primarily associated with localized solutions (Gaussian beams). He has succeeded in obtaining important results on applying Gaussian beams to the solution of multidimensional inverse problems. He made a serious contribution to the development of the boundary control method. He managed to hold a number of successful numerical experiments on the implementation of algorithms that solve inverse problems.

The results of A. P. Kachalov are contained in the monograph on inverse spectral problems, written in collaboration with M. Lassas and Ya. Kurylev (2001). For over a year, Alexander Pavlovich Kachalov is not with us - the good bright person and excellent mathematician passed away.

Translated from Zapiski Nauchnykh Seminarov POMI, Vol. 471, 2018, pp. 5-6. 